\title{
Isotachophoresis with electroosmotic flow: open versus closed systems
}

Citation for published version (APA):

Beckers, J. L., Everaerts, F. M., \& Ackermans, M. T. (1991). Isotachophoresis with electroosmotic flow: open versus closed systems. Journal of Chromatography, 537(1-2), 429-442. https://doi.org/10.1016/S00219673(01)88915-9

DOI:

10.1016/S0021-9673(01)88915-9

Document status and date:

Published: 01/01/1991

Document Version:

Publisher's PDF, also known as Version of Record (includes final page, issue and volume numbers)

Please check the document version of this publication:

- A submitted manuscript is the version of the article upon submission and before peer-review. There can be important differences between the submitted version and the official published version of record. People interested in the research are advised to contact the author for the final version of the publication, or visit the $\mathrm{DOI}$ to the publisher's website.

- The final author version and the galley proof are versions of the publication after peer review.

- The final published version features the final layout of the paper including the volume, issue and page numbers.

Link to publication

\section{General rights}

Copyright and moral rights for the publications made accessible in the public portal are retained by the authors and/or other copyright owners and it is a condition of accessing publications that users recognise and abide by the legal requirements associated with these rights.

- Users may download and print one copy of any publication from the public portal for the purpose of private study or research.

- You may not further distribute the material or use it for any profit-making activity or commercial gain

- You may freely distribute the URL identifying the publication in the public portal.

If the publication is distributed under the terms of Article 25fa of the Dutch Copyright Act, indicated by the "Taverne" license above, please follow below link for the End User Agreement:

www.tue.nl/taverne

Take down policy

If you believe that this document breaches copyright please contact us at:

openaccess@tue.nl

providing details and we will investigate your claim. 


\title{
Isotachophoresis with electroosmotic flow: open versus closed systems
}

\author{
J. L. BECKERS*, F. M. EVERAERTS and M. T. ACKERMANS \\ Laboratory of Instrumental Analysis, Eindhoven University of Technology, P.O. Box 513, 5600 MB Eind- \\ hoven (The Netherlands)
}

(First received June 7th, 1990; revised manuscript received August 8th, 1990)

\begin{abstract}
If isotachophoretic (ITP) experiments are carried out in open systems, an electroosmotic flow (EOF) will act on the ITP system. In ITP experiments with EOF in open systems four modes can be distinguished, $v i z$. , anionic, cationic, reversed anionic and reversed cationic modes. The applicability of these modes depends strongly on the velocity of the EOF. Examples of separations are given showing some typical features of these modes. Detailed consideration of a mathcmatical model for ITP with EOF showed that this model is identical with that of ITP without EOF.
\end{abstract}

\section{INTRODUCTION}

Generally, electrophoretic equipment consists of five modules, viz., (1) an anode and (2) a cathode compartment, connected to each other by (3) a separation unit, (4) a high-voltage supply and (5) a detector.

Such equipment can be used for all electrophoretic modes, viz., for isotachophoresis (ITP), zone electrophoresis (ZE), moving boundary (MB) and isoelectric focusing (IEF). The choice of the electrolytes in the separation unit and electrode compartments determines which electrophoretic mode operates. For example, for the ZE mode the whole equipment will generally be filled with the same background electrolyte, whereas for ITP a leading and terminating electrolyte will be used.

So far, ITP has been carried out in laboratory-made or commercial apparatus with closed systems, i.e., no electroosmotic flow (EOF) occurs. At present, commercial apparatus for CZE is available generally with open capillaries. Because this equipment must be suitable for ITP it is of interest to check the possibilitics for ITP in open systems, especially with regard to reproducibility and qualitative and quantitative aspects.

In this paper, a mathematical model for ITP with EOF in open systems is given, the different ITP modes are considered and some typical isotachopherograms are discussed. 


\section{THEORETICAL}

If ITP experiments are performed in open capillaries, an EOF will act on the ITP system and four different modes can be distinguished. In Fig. 1a, the situation is given for the cationic ITP mode (CM). In this instance the capillary will be filled with the leading electrolyte $\mathrm{L}$, while the terminator solution $\mathrm{T}$ will be present on the inlet side of the apparatus. The sample solution $S$ will be introduced between $L$ and $T$. The detector is placed at the outlet side. The EOF will generally act (using silica capillaries) in the direction from inlet to outlet through which the cationic ITP system will be pushed forwards with an extra velocity of the EOF compared with cationic ITP experiments in closed systems.

In Fig. $1 \mathrm{~b}$ the situation is given for the anionic ITP mode (AM). Here the cathode must be placed at the inlet side and the anode at the outlet. The capillary will be filled with the leading electrolyte $\mathrm{L}$ and the terminator $\mathrm{T}$ must be present at the inlet. This procedure can be compared with ITP with a counterflow [1] and is only useful if the velocity of the leading ions is greater than that of the EOF during the whole experiment. Remember that in this instance anionic species with mobilities lower than that of the EOF must also migrate to the anode according to the isotachophoretic condition.

If the velocity of the EOF is greater than that of the anionic ITP system, there is a net migration in the direction of the cathode. The only way to carry out the

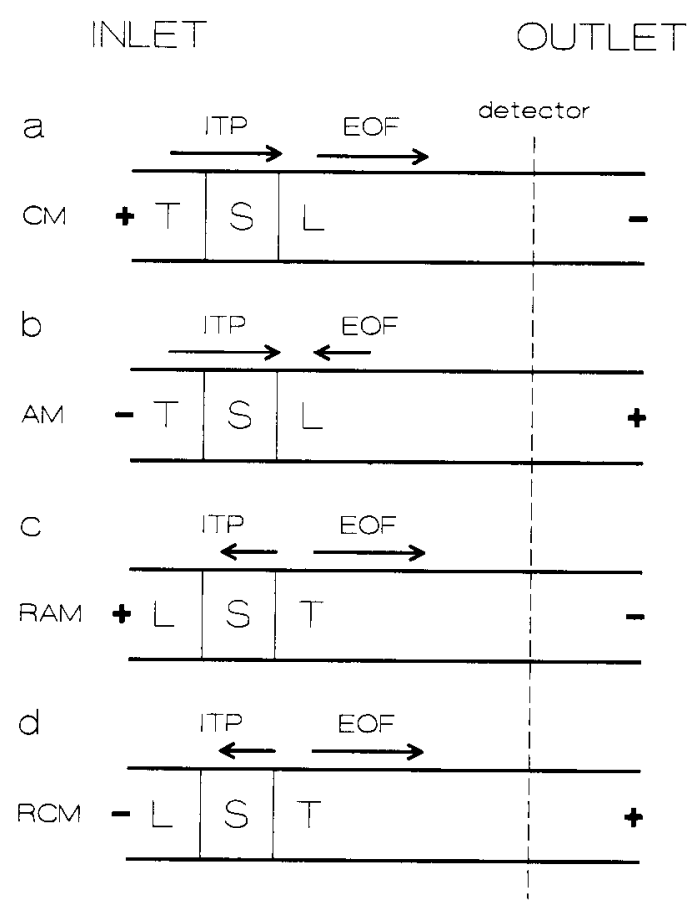

Fig. 1. Schematic representation of the four modes in ITP experiments with EOF. (a) CM represents the cationic, (b) AM the anionic, (c) RAM the reversed anionic and (d) RCM the reversed cationic mode. For further explanation, see text. 
experiments is to place the anode at the inlet side and the cathode at the outlet side (see Fig. 1c). The capillary must be filled with the terminating electrolyte $T$ and the leading electrolyte L must be present at the inlet. Although the ITP separation takes place in the direction of the anode, there will be a net velocity of the ITP system in the direction of the outlet (detector side) and the components will be detected in a reversed order compared with a normal anionic ITP system, viz., first the terminator, then all sample components with increasing mobilities and finally the leading ions. We shall call this the reversed anionic ITP mode (RAM). If the velocity of the leading ions is greater than that of the EOF, the ITP system will move to the anode and the components cannot be detected at the outlet.

Analogously to the RAM, we can consider the reversed cationic mode (RCM), which can be applied if there is a reversed EOF (e.g., using coated capillaries and/or additives to the electrolyte system) from the cathode to the anode, with a velocity greater than that of the cationic ITP system (see Fig. 1d). Here the cathode must be placed at the inlet and the anode at the outlet. The capillary must be filled with the terminator solution and the inlet vessel with the leading electrolyte. As in the RAM, the components will be detected in the reverse order. We shall not consider the RCM as this mode will generally not be useful in practice.

It will be clear that the velocity of the EOF is extremely important in the migration behaviour of ITP systems. A complicating factor is, moreover, the fact that in ITP experiments the velocity of the EOF will continuously change. At the beginning of the experiments the EOF will be determined by the composition of the electrolyte in the capillary, i.e., the leading electrolyte for a normal ITP system. During the analysis the capillary will be filled more and more with terminator solution, with a concentration and $\mathrm{pH}$ different from those of the leading electrolyte and hence with a different zeta potential and with an $E$ gradient much larger than that of the leading electrolyte according to the isotachophoretic condition. Generally, this will lead to a higher velocity of the EOF.

For non-compressible solutions it can be assumed, however, that at a certain time the velocity over the whole capillary will be constant, and thus the EOF displacement in a time span will be constant over the whole capillary. This is used in the mathematical model for ITP with EOF.

\section{The isotachophoretic model}

For the calculation of parameters of the different zones in ITP with EOF, we modified an ITP model, already published elsewhere $[2,3]$.

In this model the reduced number of parameters is always four in all zones, viz., $[\mathrm{L}]_{\mathrm{t}}$ or $[\mathrm{A}]_{\mathrm{t}},[\mathrm{B}]_{\mathrm{t}}, E$ and $\mathrm{pH}$. For all zones always four known parameters and/or equations are necessary, by means of which all parameters can be calculated. For the lcading zone the known parameters are gencrally $[\mathrm{L}]_{\mathrm{t}}$ and $[\mathrm{B}]_{\mathrm{t}}$ and the equations are Ohm's law and the electroneutrality (EN). For all other zones the four available equations are the EN, Ohm's law, the buffer equation and the isotachophoretic condition (IC).

Tiselius [4] pointed out that a substance that consists of several forms with different mobilities in equilibrium with each other will generally migrate as a uniform substance with an effective mobility given by 


$$
\bar{m}=\frac{\sum_{i=1}^{n} m_{z-i} \frac{\prod_{j=1}^{i} K_{j}}{\left[\mathrm{H}_{3} \mathrm{O}^{+}\right]^{i}}+m_{z}}{1+\sum_{i=1}^{n} \frac{\prod_{j=1}^{i} K_{j}}{\left[\mathrm{H}_{3} \mathrm{O}^{+}\right]^{i}}}
$$

For simplicity, the effect of the ionic strength is not considered in this equation. In the computer programs, however, this effect is corrected for using the Debye-HückelOnsager relationship.

Although in the general descriptions of equilibria and effective mobility of a substance, no differences exist between the leading, sample, terminating and buffer ionic species, we shall distinguish between them using the symbols $\mathrm{L}, \mathrm{A}, \mathrm{T}$ and $\mathrm{B}$. For the description of the "steady state" in ITP with EOF, we further need the mass balance of the buffer, the principle of electroneutrality, the modified Ohm's law and the isotachophoretic condition.

\section{Mass balance of the buffer}

With the mass balance of the buffer (Ohm's law and the EN must also be obeyed), the leading zone determines the conditions of the proceeding zones. The mass balance of the buffer can be derived as follows for a cationic ITP system (see Fig. 2a).

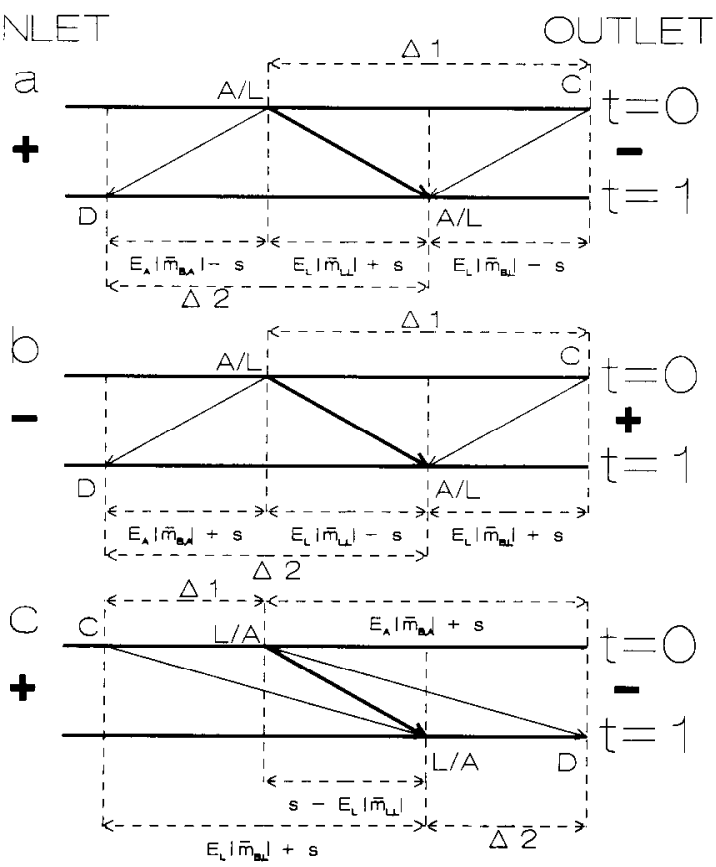

Fig. 2. Migration paths of the buffering counter ionic species over a zone boundary between a leading zone and a sample zone (L/A), for the (a) cationic, (b) anionic and (c) reversed anionic modes. For further explanation, see text. 
The zone boundary $\mathrm{L} / \mathrm{A}$ moves in a unit of time over a distance of $E_{\mathrm{L}}\left|\bar{m}_{\mathrm{L}, \mathrm{L}}\right|+s$ or $E_{\mathrm{A}}\left|\bar{m}_{\mathrm{A}, \mathrm{A}}\right|+s$, assuming that the contribution of displacement by the EOF is $s$ at a certain moment. For cationic species the displacement is increased with $s$, whereas for anions, moving in the opposite direction, the net displacement will be decreased with $s$. The anionic buffering counter ions at time $t=0$ present at the zone boundary L/A will reach point $\mathrm{D}$ at $t=1$. The distance from $\mathrm{L} / \mathrm{A}$ to $\mathrm{D}$ then will be $E_{\mathrm{A}}\left|\bar{m}_{\mathrm{B}, \mathrm{A}}\right|-s$. The buffer ionic species at $t=0$ present in point $\mathrm{C}$, will just reach the boundary $\mathrm{L} / \mathrm{A}$ at $t=1$. The distance from $\mathrm{C}$ to $\mathrm{L} / \mathrm{A}$ is then $E_{\mathrm{L}}\left|\bar{m}_{\mathrm{B}, \mathrm{L}}\right|-s$.

This means that all buffer ionic particles present in the leading zone between $\mathrm{L} / \mathrm{A}$ and $\mathrm{C}$ with a concentration of $[\mathrm{B}]_{\mathrm{t}, \mathrm{L}}$ at time $t=0(\Delta 1)$ will be present in the zone $\mathrm{A}$ with a concentration of $[\mathrm{B}]_{t, \mathrm{~A}}$ between $\mathrm{L} / \mathrm{A}$ and $\mathrm{D}$ at $t=1(\Delta 2)$. Therefore, the buffer mass balance will be as follows:

$$
[\mathrm{B}]_{\mathrm{t}, \mathbf{A}}\left(E_{\mathrm{A}}\left|\bar{m}_{\mathrm{B}, \mathbf{A}}\right|-s+E_{\mathrm{L}}\left|\bar{m}_{\mathrm{L}, \mathrm{L}}\right|+s\right)=[\mathrm{B}]_{\mathrm{t}, \mathrm{L}}\left(E_{\mathrm{L}}\left|\bar{m}_{\mathrm{B}, \mathrm{L}}\right|-s+E_{\mathrm{L}}\left|\bar{m}_{\mathrm{L}, \mathrm{L}}\right|+s\right)
$$

or

$$
[\mathrm{B}]_{\mathrm{t}, \mathrm{A}}\left(E_{\mathrm{A}}\left|\bar{m}_{\mathrm{B}, \mathrm{A}}\right| / E_{\mathbf{L}}+\left|\bar{m}_{\mathrm{L}, \mathrm{L}}\right|\right)=[\mathrm{B}]_{\mathrm{t}, \mathrm{L}}\left(\left|\bar{m}_{\mathrm{B}, \mathrm{L}}\right|+\left|\bar{m}_{\mathrm{L}, \mathrm{L}}\right|\right)
$$

or

$$
[\mathbf{B}]_{\mathbf{t}, \mathbf{A}}\left(\left|\bar{m}_{\mathbf{L}, \mathbf{L}}\right|\left|\bar{m}_{\mathbf{B}, \mathbf{A}}\right| /\left|\bar{m}_{\mathbf{A}, \mathbf{A}}\right|+\left|\bar{m}_{\mathbf{L}, \mathbf{L}}\right|\right)=[\mathbf{B}]_{\mathrm{t}, \mathbf{L}}\left(\left|\bar{m}_{\mathbf{B}, \mathbf{L}}\right|+\left|\bar{m}_{\mathbf{L}, \mathbf{L}}\right|\right)
$$

or

$$
[\mathrm{B}]_{\mathrm{t}, \mathrm{A}}\left(\left|\bar{m}_{\mathrm{B}, \mathbf{A}} \mathrm{A} /\right| \bar{m}_{\mathrm{A}, \mathrm{A}} \mid+1\right)=[\mathrm{B}]_{\mathrm{t}, \mathbf{L}}\left(\left|\bar{m}_{\mathrm{B}, \mathrm{L}}\right| /\left|\bar{m}_{\mathrm{L}, \mathrm{L}}\right|+1\right)
$$

The buffer balance in ITP with EOF is identical with that in closed systems, because the contributions of the EOF for anions and cations cancel each other. Following this procedure for anionic separations with an ITP velocity greater than that of the EOF (see Fig. 2b) and for a reversed anionic ITP system (see Fig. 2c), the same equation is always obtained.

\section{The principle of electroneutrality}

In accordance with the principle of electroneutrality (EN), the arithmetic sum of all products of the concentration of all forms for all ionic species and the corresponding valences, present in each zone, must be zero. For the electroneutrality of a zone we can write

$$
\left[\mathrm{H}_{3} \mathrm{O}^{+}\right]-\left[\mathrm{OH}^{-}\right]+\sum_{i=0}^{n_{\mathrm{A}}}(z-i)\left[\mathrm{A}^{z-i}\right]+\sum_{i=0}^{n_{\mathrm{R}}}(z-i)\left[\mathrm{B}^{z-i}\right]=0
$$

Modified Ohm's law

Working at a constant current density:

$$
E_{\mathrm{L}} \sigma_{\mathrm{L}}=E_{\mathrm{A}} \sigma_{\mathrm{A}}
$$

\footnotetext{
After applying the isotachophoretic condition (see eqn. 7)
} 
or the function

$$
R F Q=E_{\mathrm{L}} \sigma_{\mathrm{L}} / E_{\mathrm{A}} \sigma_{\mathrm{A}}-1
$$

must be zero.

The overall electric conductivity, $\sigma$, of a zone is the sum of the values $c(E \bar{m}+s) z F / E$ and consequently for a cationic separation

$$
\begin{aligned}
{\left[\mathrm{H}_{3} \mathrm{O}^{+}\right]\left(E \bar{m}_{\mathrm{H}}+s\right)-\left[\mathrm{OH}^{-}\right]\left(E \bar{m}_{\mathrm{OH}}+s\right) } & +\sum_{i=0}^{n_{\mathrm{A}}}\left[\mathrm{A}^{z-i}\right]\left[E \bar{m}_{z-i}(z-i)+s(z-i)\right]+ \\
& \sum_{i=0}^{n_{\mathrm{B}}}\left[\mathrm{B}_{z-i}\right]\left[E \bar{m}_{z-i}(z-i)+s(z-i)\right]
\end{aligned}
$$

in all zones is constant, under the condition that mobilities for negative ions are indicated with a negative sign.

Elaboration shows that for all cases the effects of the displacement of the EOF cancel each other. The consequence of this is that for electrolyte systems with an equal zone conductance, equal electric currents must be measured on applying the same electric field gradicnt, for different velocities of the EOF. To check this, the electric current and $m_{\text {EOF }}$ were measured by applying $25 \mathrm{kV}$, filling the capillary with solutions of nearly equal conductivity at different $\mathrm{pH}$. For the latter we mixed $99 \mathrm{ml}$ of a solution of $0.010 \mathrm{M}$ sodium chloroacetate with $1 \mathrm{ml}$ of a buffer (ionic strength also 0.01 ) and measured the $\mathrm{pH}$ of the mixture. The results are given in Table I.

Although the $m_{\mathrm{EOF}}$ varies from about $25 \cdot 10^{-5}$ to $70 \cdot 10^{-5} \mathrm{~cm}^{2} / \mathrm{V} \cdot \mathrm{s}$, the measured electric current is nearly constant, indicating that the conductivity of a zone is independent of the EOF.

\section{Isotachophoretic condition}

In the steady state all zones move with a velocity equal to that of the leading zone, therefore:

$$
E_{\mathrm{L}} \bar{m}_{\mathrm{L}, \mathrm{L}}+s=E_{\mathrm{A}} \bar{m}_{\mathrm{A}, \mathrm{A}}+s
$$

\section{TABLE I}

MEASURED ELECTRIC CURRENT $I, t_{\text {EOF }}$ AND $m_{\text {EOF }}$ FOR SEVERAL ELECTROLYTE SYSTEMS WITII EQUAL CONDUCTIVITY AT DIFFERENT $\mathrm{pH} \Lambda$ PPLYING $25 \mathrm{kV}$

Pressure injection $5 \mathrm{~s}$ of the EOF marker $0.001 M$ mesityl oxide; UV detection at $254 \mathrm{~nm}$.

\begin{tabular}{lllll}
\hline Buffer solution & $\begin{array}{l}\text { pH of the } \\
\text { mixed solution }\end{array}$ & $\begin{array}{l}\text { Measured } I \\
(\mu \mathrm{A})\end{array}$ & $\begin{array}{l}t_{\text {EOF }} \\
(\mathrm{min})\end{array}$ & $\begin{array}{l}m_{\mathrm{EOF}} \times 10^{5} \\
\left(\mathrm{~cm}^{2} / \mathrm{V} \cdot \mathrm{s}\right)\end{array}$ \\
\hline $0.01 \mathrm{M} \mathrm{HCl}+$ EAC & 4.70 & 18.7 & 7.26 & 26.17 \\
$0.01 \mathrm{M} \mathrm{HCl}+\mathrm{EAC}$ & 5.25 & 18.7 & 5.74 & 33.10 \\
$0.01 M \mathrm{HCl}+\mathrm{HIST}$ & 6.05 & 18.8 & 4.72 & 40.25 \\
$0.01 M \mathrm{HCl}+\mathrm{IMID}$ & 6.89 & 18.8 & 3.74 & 50.80 \\
$0.01 M \mathrm{HCl}+$ TRIS & 7.81 & 18.8 & 3.06 & 62.09 \\
$0.01 M \mathrm{HCl}+$ DEA & 8.80 & 18.7 & 2.69 & 70.63 \\
\hline
\end{tabular}


The contributions in the displacement by the EOF cancel each other.

\section{Calculation procedure}

As the effect of the displacement of the EOF is cancelled in all equations, the mathematical model of ITP without EOF can also be used for ITP with EOF. The calculation procedure is described completely in refs. 2 and 3.

\section{EXPERIMENTAL}

For all CZE experiments the Beckman (Palo Alto, CA, U.S.A.) P/ACE ${ }^{\mathrm{TM}}$ System 2000 HPCE was used. All experiments were carried out at $25^{\circ} \mathrm{C}$. An original Beckman capillary was used in all experiments. The capillary length was $57 \mathrm{~cm}$ and the distance between injection and the detector was $50 \mathrm{~cm}$; I.D. was $75 \mu \mathrm{m}$.

\section{RESULTS AND DISCUSSION}

\section{Electroosmotic flow in ITP in open systems}

The most important parameter that determines whether an ITP system can migrate in the desired mode is the velocity of the EOF, $v_{\text {FOF. }}$.

In ITP experiments, the EOF will be determined in the first instance by the electrolyte solution in the capillary, generally the leading electrolyte. Later, the capillary will be filled more and more with terminator solution. Because in ITP experiments the concentration of this terminator zone is lower than that of the leading electrolyte and there is a higher $E$ gradient, this will lead to a higher $v_{\mathrm{EOF}}$.

The $v_{\text {EOF }}$ can be measured by weighing the mass of buffer transferred from the anode to cathode (or vice versa) over a time period using a Mettler Model AE160 digital balance $[5,6]$ or placing a UV-absorbing species in the high-voltage reservoir and monitoring the UV absorption of the earth reservoir [7].

To obtain a qualitative impression of the $v_{E O F}$ we used two different approaches. One was to inject alternately leading electrolyte and a mixture of a UV-absorbing EOF marker and leading electrolyte until the whole capillary was filled. Monitoring the absorbance of the equidistant EOF marker bands in the leading electrolyte during the electrophoretic experiments gives an idea of changes in the EOF velocity. The other method was to record the voltage drop over the capillary tube at a constant electric current. For a constant EOF, the relationship between voltage drop and time should be linear.

As an example to demonstrate the changes in the $v_{\mathrm{EOF}}$ during ITP experiments, we shall consider the separation of a cationic leading and terminating electrolyte system. For ITP in closed systems for the cationic mode we can detect the leading zone $\mathrm{L}$ and the terminating zone $\mathrm{T}^{\prime}$, adapted to the conditions of the leading zone. The concentration boundary between the original terminator solution $T$ and the adapted terminating zone $\mathrm{T}^{\prime}$ does not move in ITP without EOF and will not be detected (see Fig. 3a). For ITP in open systems an extra velocity of the EOF will act on the system, independent of the electrophoretic movement. This means that the concentration boundary between the original terminator solution $\mathrm{T}$ and the adapted $\mathrm{T}^{\prime}$ zone will migrate into the capillary. If this original solution is a dilute solution of acetic acid with a high $E$ gradient and a large contribution to the EOF, the EOF increases rapidly until 


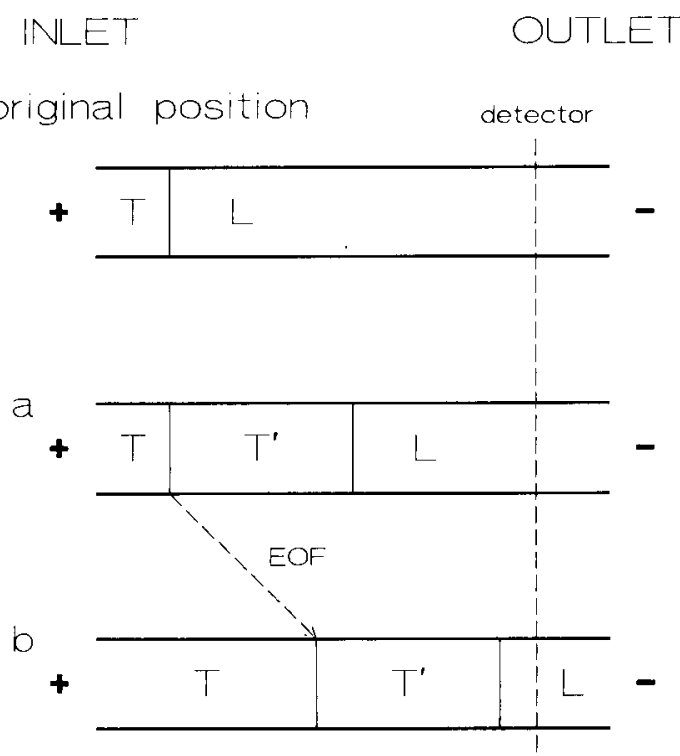

Fig. 3. Original position of leading and terminating electrolytes for the cationic mode for ITP. The zones formed during the experiment are shown for ITP (a) without and (b) with EOF. Note that the concentration boundary $\mathrm{T} / \mathrm{T}^{\prime}$ does not move without EOF, but will pass the detector by the velocity of the EOF.

the capillary is completely filled with the original terminator solution $\mathrm{T}$.

The isotachopherogram for this separation is given in Fig. 4. The capillary was alternately filled with the leading electrolyte, $0.01 \mathrm{M}$ potassium hydroxide solution at $\mathrm{pH} 5$, adjusted by adding acetic acid (pressure injection $22 \mathrm{~s}$ ) and leading electrolyte mixed with $0.002 \mathrm{M}$ mesityl oxide (pressure injection $3 \mathrm{~s}$ ). The terminating solution was

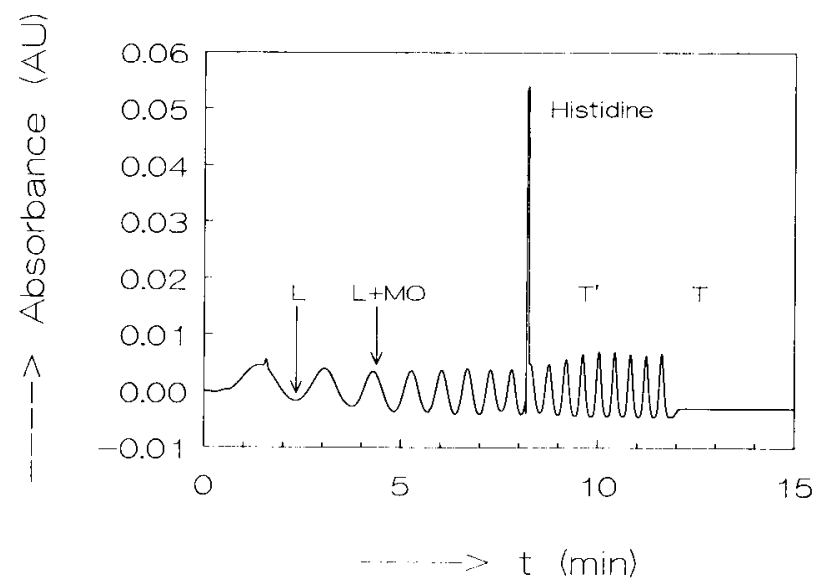

Fig. 4. Isotachopherogram for the cationic mode with a leading electrolyte $\mathrm{L}$ of potassium acetate at $\mathrm{pH}_{\mathrm{L}} 5$ and a terminator $\mathrm{T}$ of acetic acid at $\mathrm{pH} 3.5$. The leading electrolyte was alternately mixed up with $0.002 \mathrm{M}$ mesityl oxide ( $\mathrm{L}+\mathrm{MO}$ bands). The sample zone histidine indicates the transition between leading $\mathrm{L}$ and adapted terminating zone $\mathrm{T}^{\prime}$. UV detection at $254 \mathrm{~nm}$. Electric current, $4 \mu \mathrm{A}$. 
acetic acid at $\mathrm{pH}$ 3.5. The sample histidine was added to mark the transition between the leading and adapted terminating zones. Note that the time intervals between the MO peaks are decreasing, indicating that the $v_{\mathrm{EOF}}$ increases strongly during the experiment. In Fig. 5 the calculated $v_{\mathrm{EOF}}$ as a function of time is given. From the number of MO peaks over the separation length from the inlet to the detector, the distance between the equidistant peaks can be calculated and using the differences in time between the adjacent peaks the velocity at that time can be calculated.

It can be concluded that the EOF varies considerably during ITP experiments if no special precautions are taken to prevent the EOF.

\section{Cationic mode}

As an example of the cationic mode, Fig. 6 shows the isotachopherogram for the separation of sodium and lithium in a system with the leading electrolyte $0.01 \mathrm{M}$ potassium hydroxide solution at $\mathrm{pH}_{\mathrm{L}} 5$, adjusted by adding nicotinic acid. The terminator was $0.01 M$ histidine at $\mathrm{pH} 5.5$, adjusted by adding nicotinic acid. Using a UV-absorbing counter ion, nicotinic acid, the different zones show different UV absorbances because the concentrations in the sample zones are different. The leading zone $\mathrm{L}$, the sample zones of (1) sodium and (2) lithium, the $\left(\mathrm{T}^{\prime}\right)$ adapted terminating zone of histidine and $(\mathrm{T})$ the original histidine solution can be clearly seen. The UV dip (3) indicates the original sampling spot and determines the concentration boundary.

Cationic ITP experiments can easily be carried out, although the separation power is diminished compared with ITP in closed systems.

\section{Reversed anionic mode}

The requirement in order to obtain a RAM is that $E_{\mathrm{T}}\left|m_{\mathrm{EOF}, \mathrm{T}}\right|>E_{\mathrm{T}}\left|\bar{m}_{\mathrm{T}}\right|$. In that case the net migration velocity will be $E_{\mathrm{T}}\left|m_{\mathrm{EOF}, \mathrm{T}}\right|-E_{\mathrm{T}}\left|\bar{m}_{\mathrm{T}}\right|$, in the first instance. Finally, the net velocity will be $E_{\mathrm{L}}\left|m_{\mathrm{EOF}, \mathrm{L}}\right|-E_{\mathrm{L}}\left|\bar{m}_{\mathrm{L}}\right|$ and if this net velocity is greater

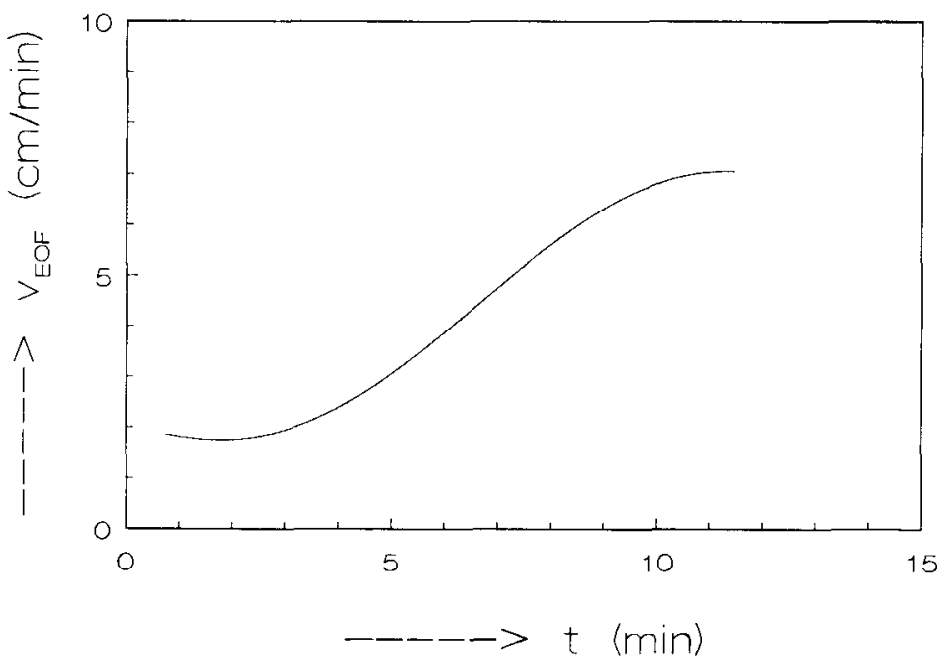

Fig. 5. Calculated $v_{\mathrm{EOF}}$ as a function of time for the experiment as described in Fig. 4. For further explanation, see text. 


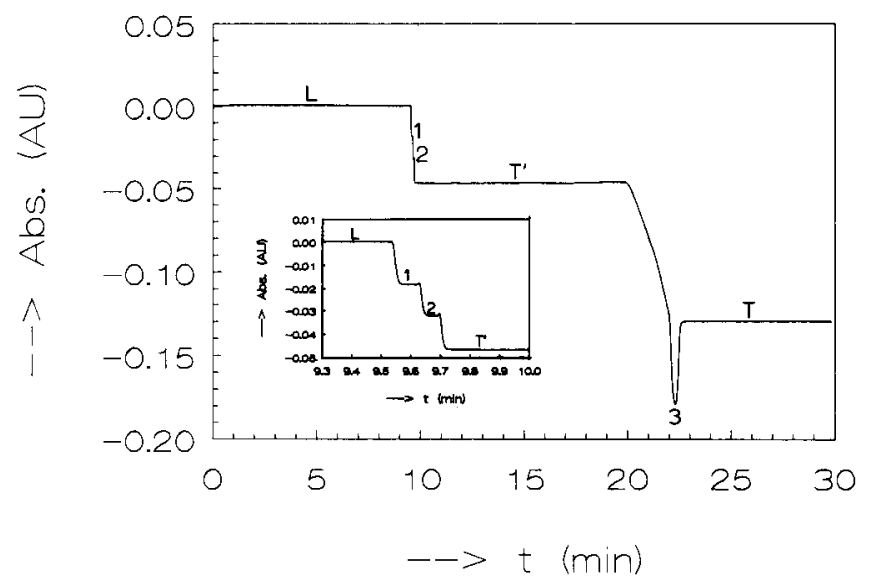

Fig. 6. Isotachopherogram for the separation of (1) sodium and (2) lithium (pressure injection $5 \mathrm{~s}$; concentrations of the sample ions $0.005 M$ ) using a leading electrolyte $\mathrm{L}$ of potassium nicotinate at $\mathrm{pH} 5$ and terminator histidine nicotinate at $\mathrm{pH}$ 5.5. Position (3) indicates the concentration boundary between $\left(\mathrm{T}^{\prime}\right)$ adapted and $(\mathrm{T})$ original terminator solution, which moves under the influence of the EOF. Electric current, $4 \mu \mathrm{A}$. UV detection at $254 \mathrm{~nm}$. The sample zones can be clearly seen in the enlarged inset.

than zero this mode can be used for separations. As an example of the reversed anionic mode, in Fig. 7 the isotachopherogram is given using as the leading electrolyte $0.0025 \mathrm{M}$ acetic acid at $\mathrm{pH}_{\mathrm{L}} 6.4$, adjusted by adding histidine, and the terminator $0.0025 M$ MES at $\mathrm{pH} 6$, adjusted by adding histidine. As the sample we introduced a solution of $0.0025 \mathrm{M}$ sodium propanoate (pressure injection $10 \mathrm{~s}$ ). Fig. 8 shows the original position and (a) the zones formed after some time in a closed system and (b) the situation expected in open systems. The zones will further be detected in the reverse order. This situation can be recognized in Fig. 7, where the order of detection is the sodium dip of the sample solution in the original $T$ zone, the transported concentration

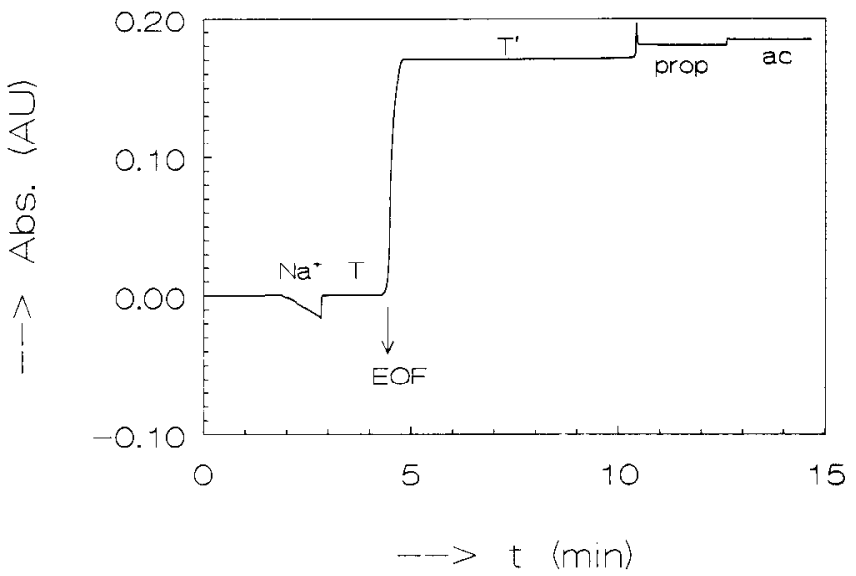

Fig. 7. Isotachopherogram for separation in the reversed anionic mode. Leading electrolyte, $0.0025 \mathrm{M}$ histidine acetate at $\mathrm{pH}$ 6.4. Terminator, MES at pH 6, adjusted by adding histidine. Pressure injection $10 \mathrm{~s}$ of $0.0025 M$ sodium propanoate. Electric current, $4 \mu \mathrm{A}$. UV detection at $214 \mathrm{~nm}$. 


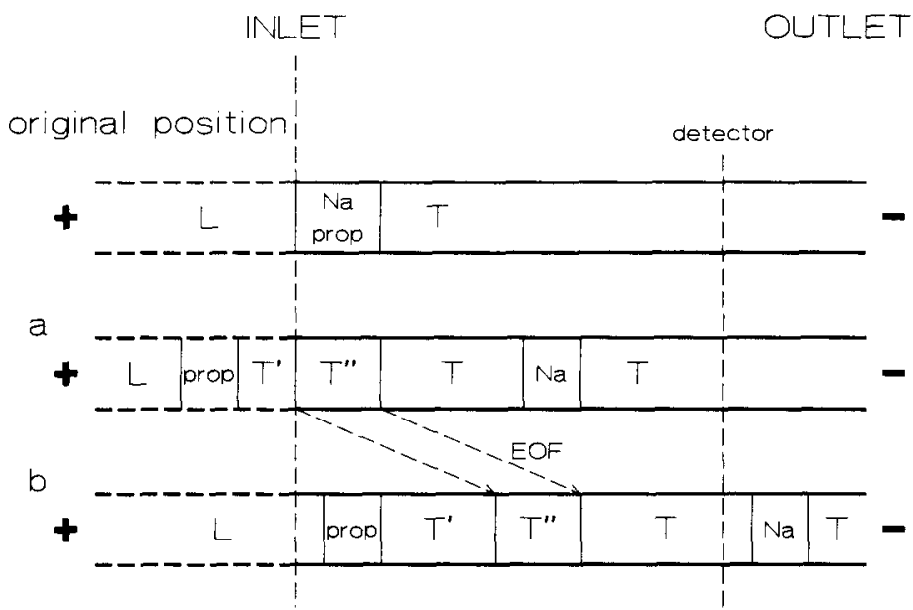

Fig. 8. Original position of the different electrolytes for the reversed anionic mode for ITP. The zones formed during the experiment are shown for ITP (a) without and (b) with EOF. Note that the separation proceeds in the direction of the anode. Without EOF the concentration boundaries $T^{\prime} / T^{\prime \prime}$ and $T^{\prime \prime} / T$ can never be detected, but as a result of the EOF they can reach the detector.

boundary between original terminator solution and adapted $\mathrm{T}^{\prime}$ zone (this transition can be marked with an EOF marker) and finally the propanoate zone and leading acetate zone. In practice, the $T^{\prime \prime}$ zone, adapted to the original sample solution, will generally be short and masked by, e.g., the UV water dip or EOF marker.

\section{Anionic mode}

The greatest problems arise in finding a good ITP system for the anionic mode. In most instances the voltage drop increased until a certain value far below that expected theoretically, indicating that the ITP system moved in the anionic mode but after a certain moment no longer moved. At a $\mathrm{pH}$ of 4 (low $v_{\mathrm{EOF}}$ ) a migrating anionic mode could be carried out, using as the terminating ion formate with a high mobility. How can this be explained?

In Table II the calculated $\mathrm{pH}, S Z R_{25}$ and concentrations are given for MES as terminator using the leading electrolyte $0.01 \mathrm{M} \mathrm{HCl}$ at $\mathrm{pH}_{\mathrm{L}} 6$ adjusted by adding

\section{TABLE II}

CALCULATED $\mathrm{pH}$ AND $S Z R_{25}$ AND CONCENTRATIONS FOR SOME TERMINATING ZONES IN ELECTROLYTE SYSTEMS AT $\mathrm{pH}_{\mathrm{L}} 6$ AND 4 AND MEASURED $m_{\text {EOF }}$ AND VOLTAGE DROP AT $15 \mu \mathrm{A}$ FOR THESE SOLUTIONS

\begin{tabular}{lcclc}
\hline Electrolyte & $\mathrm{pH}$ & $\begin{array}{l}S Z R_{25} \\
(\Omega \mathrm{m})\end{array}$ & $\begin{array}{l}m_{\mathrm{EOF}} \times 10^{5} \\
\left(\mathrm{~cm}^{2} / \mathrm{V} \cdot \mathrm{s}\right)\end{array}$ & $\begin{array}{l}\text { Voltage drop at } \\
15 \mu \mathrm{A}(\mathrm{kV})\end{array}$ \\
\hline $0.01 M \mathrm{HCl}+$ histidine & 6.00 & 10.33 & 39.6 & 17.86 \\
$0.00654 \mathrm{M} \mathrm{MES}$ & 6.43 & 42.99 & 50.94 & 73.53 \\
$0.025 M \mathrm{HCl}+\mathrm{EAC}$ & 4.00 & 4.33 & 18.54 & 7.75 \\
$0.0225 M$ formate & 4.29 & 7.62 & 24.4 & 12.6 \\
$0.0200 M$ acetate & 4.69 & 16.47 & 35.85 & 25.33
\end{tabular}




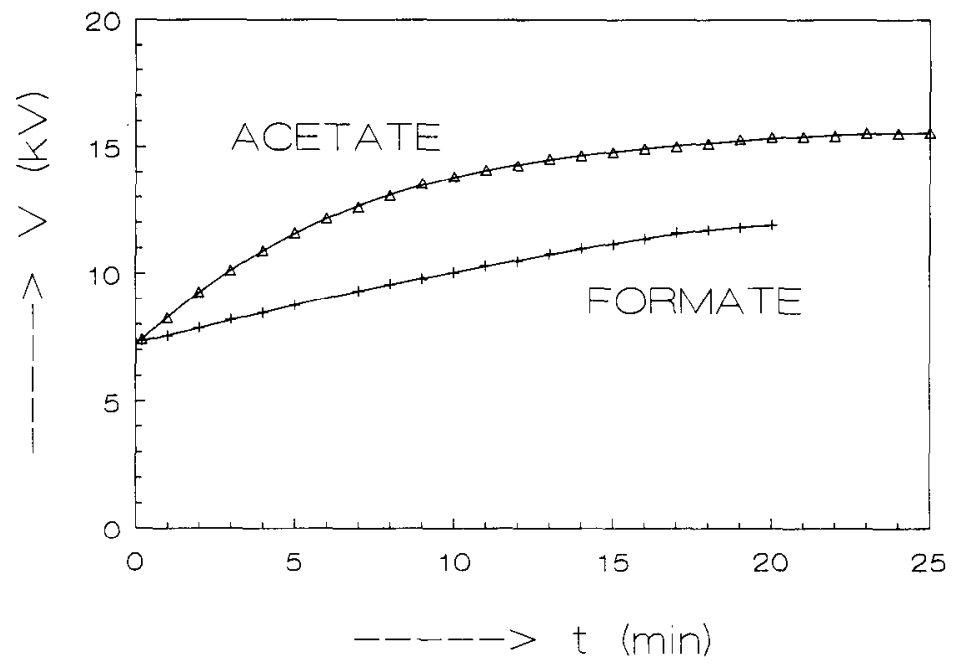

Fig. 9. Measured voltage drop as a function of time during ITP experiments with EOF in the anionic mode using a leading of $0.025 M \mathrm{HCl}$ at $\mathrm{pH}_{\mathrm{L}} 4$, adjusted by adding $\mathrm{EAC}$ and terminator solutions of $0.01 M$ sodium formate and $0.01 M$ sodium acetate. Electric current $15 \mu \mathrm{A}$.

histidine and for formate and acetate zones for the leading electrolyte $0.025 \mathrm{M} \mathrm{HCl}$ at $\mathrm{pH}_{\mathrm{L}} 4$ adjusted by adding EAC. All these solutions were carefully prepared and the $m_{\mathrm{EOF}}$ and voltage drop for these solutions were measured and recalculated to an electric current of $15 \mu \mathrm{A}$. The results are given in Table II.

In Fig. 9 the measured voltage drop as a function of time is given for acetate and formate as terminating solution in the system $0.025 \mathrm{M} \mathrm{HCl}-\mathrm{EAC}$ at $\mathrm{pH}_{\mathrm{L}} 4$. It can be seen that for formate the expected voltage drop of $12.6 \mathrm{kV}$ is fairly reached and we could see the formate step in the isotachopherogram. For acetate the expected voltage drop of about $25.33 \mathrm{kV}$ was not reached, but the voltage drop stopped at about $15 \mathrm{kV}$, which means that the ITP system came to a standstill.

The explanation is as follows. In first instance the net velocity of the ITP system is determined by $E_{\mathrm{L}}\left|\bar{m}_{\mathrm{L}}\right|-E_{\mathrm{L}}\left|m_{\mathrm{EOF}, \mathrm{L}}\right|$. Finally, the net velocity is $E_{\mathrm{T}}\left|\bar{m}_{\mathrm{T}}\right|-E_{\mathrm{T}}\left|m_{\mathrm{EOF}, \mathrm{T}}\right|$. According to the ITP condition, $E_{\mathrm{L}} \bar{m}_{\mathrm{L}}=E_{\mathrm{T}} \bar{m}_{\mathrm{T}}$. Generally $E_{\mathrm{T}}\left|m_{\mathrm{EOF}, \mathrm{T}}\right|$ will be much larger than $E_{\mathrm{L}}\left|m_{\mathrm{EOF}, \mathrm{L}}\right|$ because of the higher $E$ gradient and generally larger $m_{\mathrm{EOF}}$ (see Table II). This means that the net velocity of the ITP system will become zero during the experiment and the system will not migrate from that time.

\section{CONCLUSIONS}

The mathematical model for ITP without EOF (closed systems) is also valid for ITP with EOF (open systems). Four modes can be distinguished for ITP with EOF. The cationic mode can be applied without problems, although the available separation length is not used optimally, compared with closed systems, owing to the extra velocity of the EOF. Some precautions must be taken in the choice of the terminator to avoid strong fluctuations in the net migration velocity of the ITP system. The reversed cationic mode is of almost no value and can only be applied using additives or coated 
capillaries in order to obtain a strong reversed EOF. The reversed anionic mode can be used at high $\mathrm{pH}$ (with a high $v_{\mathrm{EOF}}$ ) and with the "counter current" of the EOF this mode can be of interest in some instances. The anionic mode is only of interest if the $v_{\mathrm{EOF}}$ is low, such as in the use of non-aqueous solvents. Otherwise, problems can be expected concerning the choice of the terminator solution. Too high $E$ gradients in the terminator solution can lead to a standstill of the ITP system during the experiments.

A first comparison between ITP in open and closed systems shows that ITP in closed systems is preferable, because no special precautions have to be taken in the choice of the electrolyte systems concerning the EOF. Unless the EOF can be strongly reduced, problems can be expected when applying ITP in open systems. The presence of an EOF, however, facilitates the use of "hyphenated" techniques, making the use of a "make-up" stream superfluous.

Experiments are currently being carried out on quantitative aspects of ITP with EOF.

\section{SYMBOLS AND ABBREVIATIONS}

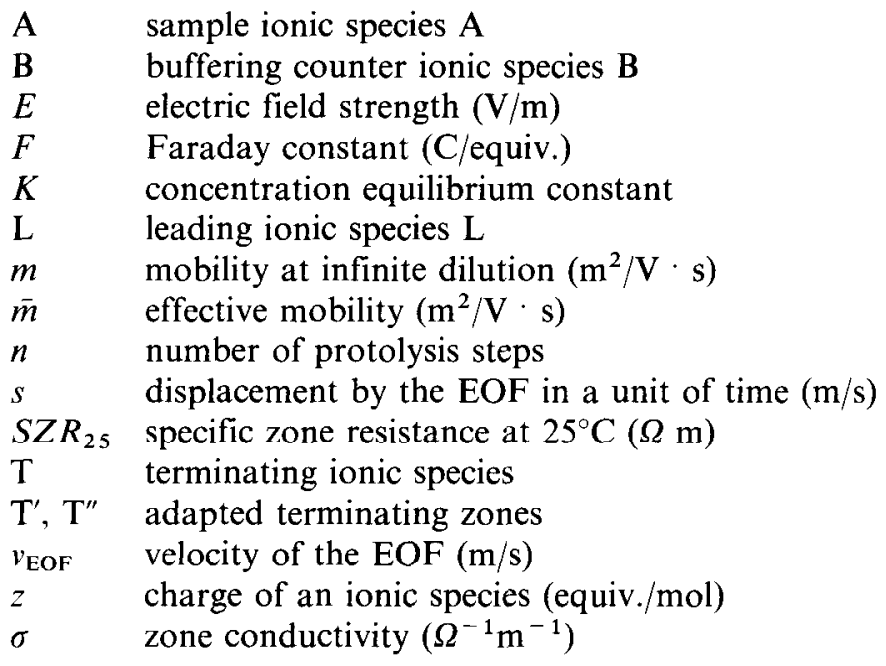

First subscript

$\mathrm{A}, \mathrm{B}, \mathrm{T}$ and $\mathrm{L}$ according to substance $\mathrm{A}, \mathrm{B}, \mathrm{T}$ and $\mathrm{L}$ $\mathrm{t}$ total

Second subscript

$\mathrm{A}, \mathrm{B}, \mathrm{T}$ and $\mathrm{L}$ in the zonc of substance $\mathrm{A}, \mathrm{B}, \mathrm{T}$ and $\mathrm{L}$

Superscript

$z \quad$ maximum charge of an ionic species

( ) $)^{i}$ to the $i$ th degree

\section{Examples}

$[B]_{t, A}$ total concentration of substance B in zone A

$\left|\bar{m}_{\mathrm{B}, \mathrm{A}}\right|$ absolute value of the effective mobility of substance B in the zone of substance 
Abbreviations

DEA diethanolamine

EAC $\varepsilon$-aminocaproic acid

HIST histidine

IMID imidazole

MES 2-(N-morpholino)ethanesulphonic acid

MO mesityl oxide

TRIS tris(hydroxymethyl)aminomethane

\section{ACKNOWLEDGEMENT}

The authors express their gratitude to the State Institute for Quality Control of Agricultural Products (RIKILT, The Netherlands) for financial support of this investigation.

\section{REFERENCES}

1 F. M. Everaerts, J. L. Beckers and Th. P. E. M. Verheggen, Isotachophoresis, Theory, Instrumentation and Applications, Elsevier, Amsterdam, 1976.

2 J. L. Beckers and F. M. Everaerts, J. Chromatogr., 480 (1989) 69.

3 J. L. Beckers and F. M. Everaerts, J. Chromatogr., 508 (1990) 3.

4 A. Tiselius, Nova Acta Reg. Soc. Sci. Ups., Ser. 4, (1930) 4.

5 K. D. Altria and C. F. Simpson, Chromatographia, 24 (1987) 527.

6 A. A. A. M. van de Goor, B. J. Wanders and F. M. Everaerts, J. Chromatogr., 470 (1989) 95.

7 T. Tsuda, K. Nomura and G. Nagakawa, J. Chromatogr., 385 (1983) 264. 